\title{
O pensar como resposta à crise na educação: contribuição arendtiana para o ensino de filosofia
}

\author{
The thinking like a responde to the education crisis: arendtian contribution to the \\ philosophy education
}

\author{
Regis Lopes Silva \\ Mestrando na Universidade Federal de Goiás, Goiânia, Goiás, Brasil. \\ regislopes@gmail.com \\ ORCID: http://orcid.org/0000-0003-2582-9539
}

Recebido em 15 de julho de 2018

Aprovado em 09 de agosto de 2018

Publicado em 17 de agosto de 2018

RESUMO: A partir de alguns conceitos do repertório arendtiano, delimitamos a crise na educação. Diante da essência do que seja a educação para Hannah Arendt e da constatação da crise, a sugestão é que a atividade do pensar, uma das três elencadas por Arendt em A vida do espírito, possa colaborar para minimizar um dos efeitos da crise, isto é, a falta de um sentido comum às experiências que vivemos e transmitimos pelo ensino. $O$ texto elabora uma revisão conceitual desta atividade e a relaciona com uma perspectiva de ensino de filosofia que prioriza o modo como o pensamento filosófico foi constituído a partir da própria atividade do pensar dos filósofos em questão.

Palavras-chave: Crise na Educação; Educação; Ensino; Pensar.

ABSTRACT: Based on some concepts of the Arendtian repertoire, we propose in this text a delimitation of the universe in which the modern crisis is, reflecting a crisis in education. In the face of the essence of what education is for Hannah Arendt and the realization of the crisis, the suggestion is that the activity of thinking, one of three listed by Arendt in The Life of the Spirit, can collaborate to minimize one of the effects of the crisis, that is, the lack of a common sense of the experiences that we live and transmit through teaching. The text formulates a conceptual review of this activity and relates it to a philosophical teaching perspective that prioritizes the way how the philosophic thought was built from the own thinking activity of each philosophers.

Key-words: Education Crisis; Education; Teaching; Thinking. 


\section{Introdução}

O presente texto se fundamenta na filosofia de Hannah Arendt. Apesar de a própria autora não se considerar uma filósofa política, não podemos nos abster de uma leitura do conjunto de sua obra realizada pelos seus interpretes e biógrafos a ponto de ser dito que "Arendt passou a vida toda falando em política, mas o seu testamento é filosófico" (Young-Bruehl apud AGUIAR, 2012, p. 12). A ideia de testamento não é trivial, pois este conceito nos ajuda a pensar como o pensamento da autora que tem apenas dois textos escritos diretamente acerca do campo educacional pôde promover tantos debates e servir de referência à inumerável produção acadêmica acerca do assunto. O testamento de Arendt é a sua extensa produção, priorizando obviamente a teoria política, que nos permite fazer diversas leituras e promover as devidas relações com o intuito de contribuirmos para o campo educacional.

Quanto à educação, como foi dito, a autora escreveu apenas dois textos: A crise na educação e Reflexões sobre Little Rock. A famosa definição acerca da educação está no primeiro texto referido. Escrito em 1958, a autora expõe em seu ensaio uma leitura do lugar que ocupa a educação por si, fato este que é justificado pelas demais obras da autora. A ideia de crise é desenvolvida e justificada com bases nos pressupostos e conceitos do repertório geral da autora, isto é, demanda uma leitura de outros textos para uma melhor compreensão deste. De início, o assunto é delimitado a partir de sua definição, "a essência da educação é a natalidade, o fato de que seres nascem para o mundo" (ARENDT, 1997, p. 223). Para uma elucidação desta definição é necessário que tomemos o conceito de mundo que, no pensamento de Arendt e numa tradição fenomenológica, desempenha um papel de extrema significância. A trajetória do texto consiste na exposição dos conceitos necessários ao debate que propomos realizar. Primeiramente a delimitação do campo conceitual através dos significados contidos na definição de educação proposta pela autora. Posteriormente, a apresentação dos motivos pelos quais é possível falar em crise na educação. Por fim, a proposta máxima deste texto, refletir com uma análise de outro conceito arendtiano um modo possível de contribuir para uma resposta à crise que se apresenta, isto é: o pensar.

\section{O mundo e a essência da educação}

Em A Condição Humana, Hannah Arendt evidencia três atividades distintas que respondem a distintas condições que a natureza nos coloca. A atividade do trabalho que responde à condição da vida biológica, isto é, o responsável pelo suprimento das necessidades que o imperativo biológico nos exige. A atividade da fabricação, a obra, esta é a responsável pela criação de um mundo no qual podemos nos mover, um mundo que assegura o caráter de continuidade e comunidade. "A obra proporciona um mundo 'artificial' de coisas, nitidamente diferente de qualquer ambiente natural" (ARENDT, 2015, p. 9). Por fim a ação, que diz respeito à esfera da liberdade. Essa atividade responde pela condição inalienável da pluralidade. Com estas divisões Arendt não pretende hierarquizar as 
atividades, o intuito é evidenciar como elas se relacionam e de que modo nos é assegurada a plenitude do ser humano quanto àquilo que nos foi dado a ser, a chamada vita activa.

É necessário, como mencionado, certa noção acerca de distintos conceitos arendtianos para que possamos pensar a educação juntamente com a autora. Dentre as três atividades supracitadas, a obra é aquela que mais diz respeito à atividade docente. Analisando o conceito de mundo, as coisas que nele há "têm a função de estabilizar a vida humana" (ARENDT, 2015, p. 170). O mundo diz respeito a

tudo aquilo que é testemunho duradouro da presença humana sobre a Terra, seja a construção de utensílios, ferramentas e obras de arte, seja a edificação de um espaço comum de copresença e interrelação, seja a comunidade dos homens sobre a Terra, seja o conjunto dos que amam o mundo e por isso o constituem (CORREIA, Adriano apud PASSOS, Fábio, 2014, p. 3).

A partir disto torna-se claro a essência da educação, o fato de que novos nascem em um mundo que já existe antes deles e que existirá após a morte destes. A educação desempenha a função de apresentar o mundo tal como ele é a estes que nele entram. A educação não é um mero ensinar a viver ou uma instrução que deveria se preocupar exclusivamente com a esfera da reprodução da vida, isto é, um ensinar a arte da preservação.

Se a criança não fosse um recém-chegado nesse mundo humano, porém simplesmente uma criatura viva ainda não concluída, a educação seria apenas uma função da vida e não teria que consistir em nada além da preocupação para com a preservação da vida e do treinamento e na prática do viver que todos os animais assumem em relação a seus filhos (ARENDT, 1997, p. 235).

O fato da natalidade assegura uma pluralidade, a cada nascimento, com ele, nasce a possibilidade do novo. A educação em Arendt é conservadora no sentido de conservar o mundo protegendo-o da novidade irrestrita, também conservar os novos contra um mundo que eles não conhecem. Mais do que apresentar a estes os meios pelos quais eles asseguram a subsistência, a atividade do trabalho, cabe à educação apresentar o mundo que já existe e no qual eles podem se sentir em casa, pelo próprio caráter de estabilidade que o mundo confere. Por este motivo, a política não se identifica com a educação, este campo é pré-político. A política para Arendt "é o campo da ação, da espontaneidade e da liberdade pública, onde iguais decidem, em voz e ato, e se responsabilizam com os destinos e questões que dizem respeito a todos" (ALMEIDA, 2012, p. 135).

A educação presume a hierarquia entre as partes, o que não significa autoritarismo e, pela própria preservação da potência de novidade presente nos educandos, a estes não podemos delegar a responsabilidade pelos assuntos de que trata a política. A educação, conforme Arendt, se localiza entre o âmbito privado e o público, sua 
categorização como pré-política se refere a esse espaço intermediário. A natalidade é o que possibilita a ação como modo de participação política, mas a educação se efetiva de fato numa preservação dessa potencialidade e na promoção dos elementos necessários para que possa tornar os jovens "de uma parte, a dominar os pré-requisitos curriculares técnico-científicos e, de outra, a se integrarem nessa herança pública que lhes pertence por direito" (CARVALHO apud ALMEIDA, 2012, p. 137).

O caráter pré-político da educação se constitui, essencialmente, na perspectiva de que é através dela que aos novos é dada a possibilidade de serem inseridos no mundo. A partir de então, essa situação de pertencimento ao mundo, possam então aparecer e agir em liberdade com os demais. Cada nascimento é, em si, natalidade, portanto carrega uma potência de novidade e pluralidade, mas este nascimento demandará uma apresentação do mundo que aí está e como está. A educação não é o lugar em que se transforma o mundo, esse lugar é a política, mas é o que o apresenta e dá as condições necessárias para que as pessoas possam, então, fazer parte do mudo comum e, dentre as coisas que aqui existem, a fazer parte da política. "Esse vínculo entre natalidade e ação é reafirmado em toda a obra de Arendt e é decisivo para pensar a relação entre educação e política” (CORREIA apud CARVALHO. 2017, p. XVII).

\section{A crise}

Um aspecto da crise é intrínseco ao campo da educação, isto é, a crise é uma situação em que nossas respostas não são suficientes às perguntas que o tempo nos coloca, nós "perdemos as respostas em que nos apoiávamos de ordinário sem querer perceber que originariamente elas constituíam respostas a questões" (ARENDT, 1997, p. 223). Sabendo que a educação é algo que jamais pode ser concebida como acabada em definitivo, completa e finalizada, esta abertura perene nos indica, por uma perspectiva, uma crise perene. O fato de o humano existir enquanto um ser plural acarreta que a educação é um constante entre e vive sob a atmosfera de um paradoxo. Educam-se os novos porque nascem em um mundo que já existe e deve ser preservado e apresentado, todavia nestes que nascem ocorre a marca inalienável da possibilidade do novo e das mudanças. A crise por si mesma não significa uma situação de desamparo.

A falta de respostas definitivas não acarreta uma destruição do mundo comum ou o fracasso da educação. A crise assumiria um caráter desolador se esta característica fosse obliterada. O grande problema que se apresenta no que tange o ensino é uma confusão de fronteiras das atividades humanas. Isto é, a atividade docente, o ensino, que pelo seu próprio estatuto jamais poderia ser concebido semelhante à fabricação de algo, tem sido destinado, sobretudo a partir da segunda metade do século XX ao campo da fabricação do animal laborans, um ente capacitado e treinado exclusivamente para o âmbito da preservação da vida, o campo do trabalho. Tal perspectiva ocasiona uma corrupção do mundo comum pois o resultado da atividade do trabalho é o consumo, resultando deste a absorção corpórea do que foi consumido ou o seu descarte. 
Restando apenas o "caráter instável e inóspito de um mundo quase inteiramente regido pela lógica do trabalho e do consumo, isto é, pela lógica da produção e da destruição em escala global e em ritmo cada vez mais acelerado" (ARENDT apud Duarte, 2010, p. 5).

A educação é justamente o modo pelo qual transcendemos essa esfera da reprodução cíclica, "para Arendt, a educação tem por tarefa familiarizar os educandos com experiências e compreensões compartilhadas, instituições e práticas, saberes e pensamentos que foram constitutivos para o mundo" (ALMEIDA, 2010, p. 3). Não se trata de negar esse aspecto da vida humana, mesmo porque o trabalho é um imperativo ao qual a necessidade nos coloca. A questão é suprimir todas as demais esferas da existência unicamente a uma relação de trabalho e consumo. A educação, ainda que não seja um espaço político, tem sido utilizada por interesses privados que se valem do espaço público para determinarem um tipo de existência que vá ao encontro de suas demandas. $O$ ensino não existe enquanto uma atividade alheia ao social e, a depender do modo como ele é visto pelos educadores, assumirá vez ou outra uma tendência mais ou menos humanista.

O sistema de ensino sempre se ordena em função de uma representação da educação, de uma representação que implica um desejo - desejo de os indivíduos alcançarem, com sua formação, uma certa maneira de ser, de trabalhar, de ser relacionarem entre si na sociedade (LEFORT, 1999, p. 208).

Obviamente não cabe à educação salvar o mundo, mudando-o, mas protegê-lo contra a voracidade da atividade que o consome. Negando a primazia de um ensino utilitário, este em que se prioriza um domínio de técnicas e saberes aos quais a finalidade já foi definida de antemão, condenando o fazer educativo à semelhança da oficina do artesão, negar isto faz com que a educação acolha "a indeterminação, já que quem aprende está sendo requisitado, não tanto para dominar um certo lote de conhecimentos, mas sim para travar um novo relacionamento com o saber" (LEFORT, 1999, p. 211).

A fragilidade de homens que não colocam em questão seus princípios e suas finalidades condena todo um passado que deve ser legado aos novos à mera serventia quanto ao que é útil ou não. A utilidade diz respeito à obra, é na fabricação que se vislumbra uma finalidade para aquilo que é feito. Conforme Lefort (1999, p. 223), há um despojamento completo do sujeito no intuito de perpetuar as condições necessárias a uma sociedade da técnica e do trabalho. Nenhuma dimensão estética e ética pode ser contemplada se as instituições que historicamente promoviam essas reflexões não são mais do que lugares vazios de sentido e plenos de verdade. Cabe à educação apresentar o mundo tal como ele é e a sua história, inclusive desvelando essa condição instrumental à qual estão submetendo a relação de ensino.

Retomando a ideia de uma crise, que inevitavelmente se apresenta, não é a insuficiência das respostas que a agrava ou a constitui. Negá-la apenas colabora para os discursos tecnicistas uma vez que poucos espaços restaramà exceção destes em que aúnica relação existente 
e possível é determinada pelo trabalho e consumo. A educação tem o dever de apresentar estas condições de existência, ainda que não haja respostas imediatas a elas. É no reconhecimento de uma crise que podemos justamente refletir acerca da possibilidade de que outras atividades, dentre elas as do espírito, apareçam como contribuições à atividade do ensino.

\section{O pensar}

As faculdades do espírito ganham destaque no pensamento de Arendt, sobretudo, após o julgamento de Adolf Eichmann. Eichmann foi um funcionário nazista altamente responsável pela chamada "solução final". Arendt foi enviada pela revista New Yorker para acompanhar o julgamento e a resolução do caso envolvendo o acusado. $O$ que the causou surpresa foi a personalidade fraca de Eichmann, longe de ser um monstro ele se assemelhava mais a um burocrata qualquer que desempenhava suas funções sem se dar o trabalho de pensar o significado delas e as suas consequências reais.

\footnotetext{
Ele sempre fora um cidadão respeitador das leis, porque as ordens de Hitler, que sem dúvida executou o melhor que pôde, possuíam "força de lei" no Terceiro Reich [...] e quanto a sua consciência, ele se lembrava perfeitamente de que só ficava com a consciência pesada quando não fazia aquilo que lhe ordenavam (ARENDT, 2011, p. 35 - 37).
}

Longe de ser tido como algum insano ou psicopata, seu caso não se aproximava nem do ódio anti-semita, doutrinação ou algum tipo de perseguição religiosa. O que mais caracteriza a adesão de Eichmann ao regime foi a possibilidade que a História lhe concedeu de fazer parte de algo supostamente grandioso e que estava em curso. Alguém sem grandes perspectivas quanto à própria vida viu no movimento nazista uma oportunidade de "começar de novo e ainda construir uma carreira" (ARENDT, 2011, p. 45).

Questões como esta levaram Arendt a se perguntar pela conexão da faculdade de pensar com aspectos éticos que envolvem os problemas acerca de realizar ou não o mal. "Seria possível que a atividade do pensamento como tal [...] estivesse dentre as condições que levam os homens a se absterem de fazer o mal, ou mesmo que ela realmente os 'condicione' contra ele" (ARENDT apud ALMEIDA, 2011, p. 150). A atividade de pensar a realidade, as experiências, tem uma razão de ser que envolve as questões éticas e culminam num pertencimento ao mundo porque o que se questiona, em último caso, é se é possível garantir a continuidade e permanência de um mundo em que o mal é banal porque qualquer relação estabelecida com o mundo e sua pluralidade é instrumentalizada e individualista.

"Não só conhecer o mundo, mas também questionar o que ocorre nele, buscar compreender suas histórias e estabelecer uma relação própria com esse espaço comum e seu legado" (ALMEIDA, 2011, p. 146), são estas relações que se estabelece com o conteúdo do mundo que faz com que ele se apresente como um lugar hospitaleiro a nós. 
É possível tanto conhecer o mundo quanto pensá-lo, esta distinção é importante para que localizemos a atividade do pensar como uma contribuição às respostas que a crise exige. É no pensar que estabelecemos algum tipo de vínculo com um mundo que não foi criado por mim, mas ao qual posso fazer parte. Conhecer o mundo me faz saber o que ele é, pensa-lo faz com que eu possa estar nele e me sentir parte com os demais. Mas não é possível que alguém se sinta parte daquilo que sob uma perspectiva se coloca como disponível ao consumo, retomando a questão do ensino como instrumentalização do saber. O objeto do consumo se desfaz no próprio ato de consumi-lo e essa confusão de lugares e atividades não permite que o mundo acolha os que nele chegam, pois os que chegam o fazem apenas para devorá-lo. Não há sentido em fazer parte de algo que está fadado à ruína, não há quem queira responsabilizar-se pelo efêmero. Pensar carrega consigo um risco quando exacerbada a sua atividade e quando esta se faz sem nenhuma referência ao mundo, nisto está a crítica histórica de Arendt à filosofia política e a sua crítica aos intelectuais que aderiram ao regime nazista. $O$ risco do pensamento, "essa retirada do mundo, embora necessária para a atividade do espírito, expõe o eu pensante ao risco de se isolar das experiências reais e girar apenas em torno de si mesmo" (ALMEIDA, 2010, p. 5).

Corre-se o risco de se esquecer da responsabilidade pelo mundo, por isso o pensar se vincula necessariamente à responsabilidade e ao amor mundi. O que define o pensar é o sentido. Esta atividade não é determinada pelo seu conteúdo, mas sim pela intenção contida no seu exercício. Pensar é trazer o conteúdo do mundo a um tipo de existência na qual eu posso me movimentar através da imaginação. "A imaginação, portanto, que transforma um objeto visível em uma imagem invisível, apta a ser guardada no espírito, é a condição sine qua non para fornecer ao espírito objetos-de-pensamento" (ARENDT apud ASSY, 2015, p. 62). Objetos de pensamento não se identificam a objetos memorizados. A imagem do objeto fica retida na memória tão logo o referente externo deixe de produzir a sensação correspondente. Ter um objeto de pensamento implica tornar presente para si através de um esforço de concentração aquilo que naturalmente está ausente. Este esforço do espírito, o lidar com coisas que estão ausentes, permite outro nível desta atividade de ter para si objetos, uma atividade que vai "em direção ao entendimento das coisas sempre ausentes, e que não podem ser lembradas, porque nunca estiveram presentes para a experiência sensível" (ARENDT, 2014, p. 96).

Dentro desta interpretação localizamos o modo de existir conceitual, isto é, todas as discussões éticas e estéticas produtoras de perguntas como "o que é a justiça" ou "o que é o belo" lidam com um tipo de coisa sempre ausente. Aquilo que se pode dizer que uma vez esteve presente e agora não mais são atos de justiça, objetos portadores de beleza, mas não o conceito em si. O significado sempre será fruto do pensamento. "Todo pensamento deriva da experiência, mas nenhuma experiência produz significado ou mesmo coerência sem passar pelas operações de imaginação e pensamento" (ARENDT, 2014, p. 106).

Através disto que propomos o conceito de pensar arendtiano como uma referência que possa colaborar com a questão do ensino. Se no âmbito da educação o que está em jogo é o fato de que há uma geração a ser educada, a ser inserida num universo de imagens e coisas 
produzidas pelos humanos, a mera instrução não possibilitaria a plena inserção destes novos no que Arendt chama de mundo. Negligenciando a ideia do pensar enquanto uma atividade do espírito distinta do conhecer propiciamos uma condição na qual "a ausência do pensamento [...] ensina a aderir rapidamente a tudo o que as regras de conduta possam prescrever em uma determinada época para uma determinada sociedade" (ARENDT, 2014, p. 199).

Sejam essas regras oriundas de um regime político tal como o Nazismo, explicando a fácil adesão não só de Eichmann mas da grande maioria da nação alemã, sejam essas ideias apresentadas como slogans no universo educacional, tais como "ensino de qualidade", "promoção da cidadania", "capital humano", etc.

A necessidade de pensar jamais pode ser satisfeita por insights supostamente precisos de 'homens sábios'. Essa necessidade só pode ser satisfeita pelo próprio pensamento, e os pensamentos que tive ontem irão satisfazer essa necessidade hoje apenas porque quero e porque sou capaz de pensa-los novamente (ARENDT, 2014, p. 107).

O sentido dos fatos, das expressões, o que se conhece não é dado de modo definitivo. O sentido "pode surgir quando transformamos meros fatos em uma história (estória, story) humanamente compreensível. Com isso, no entanto, não se chega a um sentido definitivo. Pelo contrário, a cada acontecimento é preciso começar a reflexão de novo" (ALMEIDA, 2011, p. 148). Isto implica dizer que o pensar é algo perene e que não há coisa no mundo que não possa ser colocada sob essa atividade do espírito.

É necessário que aquele que pensa se retire desse mundo das aparências, este fato, que para Arendt significa a única condição anterior ao pensamento pode trazer elementos relevantes quando pensamos a questão do ensino. "Todo pensar exige um pare-e-pense" (ARENDT, 2014, p. 97), portanto uma quebra no fluxo de acontecimentos no mundo, inclusive uma aula. Todavia, este sair do mundo não acarreta solidão, mas solitude. $\mathrm{Na}$ solidão, a própria capacidade de pensar já se faz comprometida. O solitário não consegue ter a companhia nem de si mesmo. A solitude, numa leitura de Bethania Assy, diz que

ao fazermos companhia a nós mesmos, somos capazes da experiência do pensamento. A matéria-prima que é modelada pelo pensar é a experiência. A solitude de quem pensa, de forma alguma, é desconectada de experiências, sejam elas pessoais, históricas, culturais ou fictícias (ASSY, 2015, p. 89).

Isto quer dizer que ainda que o sujeito se retire do mundo ele não se retira em absoluto, isto é, o pensamento que ocorre está vinculado necessariamente a conteúdos do mundo, conteúdos de experiência. "A habilidade de pensar, que permite ao espírito retirar-se do mudo, sem jamais poder deixa-lo ou transcende-lo" (ARENDT apud ALMEIDA, 2011, p. 151). Mas não somente, outra relação que se estabelece a partir dessa retirada do mundo no pensamento é o diálogo consigo mesmo, o que supõe a 
existência de outros "uma vez que a pluralidade é uma das condições existenciais básicas da vida humana na Terra [...] estar sozinho e estabelecer um relacionamento consigo mesmo são a característica mais marcante da vida do espírito" (ARENDT, 2014, p. 92).

\section{Pensar com Sócrates}

Para resgatarmos essa questão da pluralidade que é intrínseca à atividade de pensar faremos uma análise da figura de Sócrates sob a ótica de Arendt e seus comentadores. Sócrates é conhecido pelo seu método dialógico no qual ele realizava diferentes perguntas acerca de um tema definido no intuito de exercitar uma atividade em si e no seu interlocutor, a atividade do pensar, uma vez que não necessariamente este jogo de perguntas e respostas conduzia a algum conhecimento de fato. Sócrates é visto como uma referência quando o que está em discussão é a atividade do pensar e podemos analisar a sua relação com tal atividade por três metáforas.

A primeira compara Sócrates a uma arraia-elétrica. Nesta imagem observamos o caráter paralisante do pensamento. A arraia-elétrica paralisa aqueles que nela tocam. Assim é o pensar, paralisa o fluxo contínuo de acontecimentos e, ao mesmo tempo, o próprio sujeito que pensa. Esta característica do pensar pode ser tomada como o espanto, uma potência de "provocar perplexidade, paralisar e interromper argumentos tidos como dados" (ASSY, 2015, p. 66). Primeiramente o pensar lhe retira do senso comum e aquilo que assumia um caráter autoevidente, portador de uma áurea verdadeira, ou empobrecido de sentido, perde todo o seu estatuto e se coloca como objeto de pensamento, algo ainda não acabado.

A segunda imagem socrática o compara a um moscardo. Quanto a essa comparação, a leitura de Arendt é que aqui o pensar se refere a um autoexame, portanto o revelador da própria consciência. "A palavra consciência tem origem no grego syn-eidenai, cujo significado original remetia apenas à noção de consciência de si” (ASSY, 2015, p. 67). Ela é a responsável por nos fazer aparecer a nós mesmos gerando aquilo que Arendt chama "dois-em-um". Por essa característica resgata-se a questão da pluralidade, é um exercício que aponta para o fato de que não estou sozinho no mundo. Segundo Valée, analisando alguns pontos acerca deste conceito em Arendt, o pensar por si não unifica o ser pensante, a característica dual do pensamento não possibilita a ideia de unidade do sujeito se esta atividade não fosse interrompida ocasionando um retorno do pensar consigo, gerador de ambiguidade, para um mundo marcado pela pluralidade. "Para ser confirmado na minha unidade, eu dependo inteiramente dos outros" (1999, p. 31). Assim como também não haveria a possibilidade do pensamento, tal como o exercido por Sócrates, se o pensar não exercesse a função de testemunha, isto é, o fato de que "deve estar-se diante de si como diante dos outros.

A testemunha interior é, pois, o representante da pluralidade; e o diálogo na solidão interioriza o ponto de vista dos outros" (VALÉE, 1999, p. 32). A importância da ideia de pluralidade é fundamental para esta compreensão uma vez que é o conceito 
com o qual o pensar está se relacionando de distintos modos. Para pensar é necessário que eu tenha a experiência do que seja o outro, um alguém que não seja eu. Portanto, reconhecer vozes no mundo que não a minha. Ao mesmo tempo, quando me recolho ao pensamento me torno o dois-em-um, um conceito de Arendt, e para que não me perca na ambiguidade de ser inerente à própria atividade é necessário que um outro me desperte do pensamento e, assim, eu tenha visão da unidade que sou. Eu sou um na medida em que outro me desperta da ambiguidade que é ser dois-em-um.

Tal dualidade do pensar significa que qualquer atividade da consciência será marcada por esta pluralidade à qual não se pode negar sem o prejuízo de tornar-se algo menor do que um humano. Oindividual não pensante e solitário. "Todas as atividades do espírito testemunham, elas próprias, porsua natureza reflexiva, uma dualidade inerenteà consciência"(ARENDT, 2014, p. 93).

Por fim, a terceira representação acerca de Sócrates diz respeito ao modo como a experiência de pensamento permite uma doxa, comumente traduzida por opinião. Neste momento Sócrates desempenha uma atividade tal como a do parteiro. "Para Sócrates, como para seus concidadãos, a doxa era a formulação em fala daquilo que dokei moi, daquilo que me aparece" (ARENDT, 1993, p. 96). A doxa é o resultado de uma visão de mundo, do mesmo mundo no qual todos os demais se encontram. Ao pensar sobre este mundo que me aparece eu teço elementos que não são os mesmos resultantes do pensar de outros que ocupam lugares no mundo distintos do meu. Isto não significa que a doxa se oponha à verdade, para Arendt, essa doxa

não era fantasia subjetiva, arbitrariedade, e tampouco alguma coisa absoluta e válida para todos. $O$ pressuposto era de que o mundo se abre de modo diferente para cada homem, de acordo com a posição que nele ocupa; e que a propriedade do mundo de ser o "mesmo", o seu caráter comum, ou "objetividade", reside no fato de que o mesmo mundo se abre para todos e que a despeito de todas as diferenças entre os homens e suas posições no mundo tanto você como eu somos humanos (ARENDT apud ASSY, 2015, p. 71).

Diante destas três figuras, às quais podemos atribuir o modo de pensar socrático, podemos pensar, também, o quanto isto é significativo para o campo do ensino no que tange a educação institucional. $O$ fato de ser Sócrates não é mero acaso, tal filósofo é tido por Arendt como o modelo de pensador. Não que devamos repetir o seu modo de vida ou o seu próprio pensar. Impossível pelas próprias características que esta atividade carrega. Através da figura socrática podemos analisar por óticas diferentes uma mesma atividade, a atividade do espírito que é o pensar. O pensar carrega consigo a interrupção de um fluxo de informações, acontecimentos, fatos para colocar em diálogo consigo mesmo aquele que se propôs a pensar. Portanto é de extrema urgência resgatarmos essa esfera de atividade em um mundo marcado pela velocidade e efemeridade do que é construído em comum.

O pensar também revela uma pluralidade inerente à condição humana, nada mais necessário termos ele como referência para a prática docente. O pensar revela minha 
consciência ao mesmo tempo que expõe a existência de consciências que não sou eu, colaborando assim para a construção de uma ideia de comunidade que finda no terceiro elemento acerca da pessoa de Sócrates. Obviamente a doxa não foi pensada no campo do ensino, da educação, mas sobretudo para o âmbito da política num contexto em que as decisões que darão o rumo para a cidade são realizadas através da persuasão, da palavra falada.

$\mathrm{Na}$ educação lidamos com aqueles que não possuem necessariamente uma doxa porque a posição que eles ocupam no mundo ainda está por se fazer, cabendo parte desta posição à educação. Todavia, não podemos nos eximir de considerar essa expectativa da atividade humana. Um campo no qual não é a verdade que está em questão e não a temos como a finalidade última. Trata-se da constituição de um lugar no qual a construção de um mundo coletivo é a finalidade, não o fim. Um campo em que àqueles que aprendem é dado a possibilidade de construírem significados para o conjunto de coisas que são os objetos primeiros da atividade educacional. Não significa negar a essência da educação tal qual Arendt expos, menos ainda querer introduzir elementos políticos num campo que deve ser pré-político. Mas uma resposta à crise de sentido que assola a modernidade numa perspectiva que valorize ainda mais a educação, que é um dos lugares responsáveis pela permanência do mundo comum. O resgate do conceito de pensar, como aqui foi feito, teve como companhia perene a ideia de que há um mundo e ele deve ser anunciado e preservado - objetivo da educação. Numa sociedade em que a eficácia do resultado, o imperativo da verdade, a promessa da utilidade é colocada como benefícios necessários aos alunos, tais alunos devem no mínimo possuir as condições de pensarem não o lugar que eles ocupam no mundo, mas aquele que, se nada for feito, ocuparão.

\section{Ensino de filosofia}

Pensar com Sócrates é pensar fugindo de uma lógica que busca a verdade enquanto significação, aquela que identifica "a verdade como o fim do pensamento" (ASSY, 1999, p. 37). Toda atividade Socrática, seus diálogos não aconteciam em vista de um saber. Não era por amor ao conhecimento que Sócrates questionava, mas por amor ao questionamento. O pensar é uma atividade que não pode ficar à margem do ensino justamente porque é através dele que atribuímos sentido àquilo que fazemos. Esses referenciais arendtianos possibilitam um diálogo com qualquer saber a ser ensinado uma vez que a proposta mais se assemelha a uma prática do que a um conteúdo especificamente. Evidentemente, quanto ao ensino de filosofia, temos uma real possibilidade na sua abordagem em sala de aula. Sobre os conteúdos, lidamos com as obras filosóficas diretamente e assumimos que a aula de filosofia possa se tornar um diálogo profícuo com pensamento de outros, os filósofos. A filosofia historicamente se manteve como a disciplina que permite a problematização de questões que nos são próprias enquanto humanos, nos permite, inclusive, problematizar o próprio significado do que seja a filosofia e a sua história. 
O que nos foi legado, de modo geral, não diz respeito à atividade do pensar, mas a seus resultados: os sistemas filosóficos e as doutrinas. Se quisermos saber algo sobre o próprio processo pensante de seus autores, é preciso descobrir o que não foi descrito de modo direto. O caminho é ler os escritos indagando quais foram as questões e acontecimentos que os antecedera e qual foi a experiência do eu pensante (ALMEIDA, 2011, p. 158)

Ensinar filosofia propondo essa perspectiva do pensar, isto é, trazendo à tona essa atividade do espírito tal como Arendt a descreveu, assim poderemos contextualizar de outra forma a história do filósofo, dessa vez sob a perspectiva da produção da sua obra enquanto resultado de um pensamento. Ao se pensar o pensamento de outros, também, evidenciamos uma característica inalienável do pensamento filosófico, a sua pluralidade. Há um movimento do pensamento filosófico que faz com que aquelas questões que nos são próprias, da condição humana, sempre voltem a nós porque nunca são por fim estabelecidas, "Os resultados da reflexão são provisórios e experiências diferentes ou novas desafiam a repensar aquilo que acreditava já ter pensado" (ALMEIDA, 2011, p. 163).

É preciso ultrapassar o mero pragmatismo ofuscado por uma noção de eficácia, portador da nova verdade e tão presente nos discursos educacionais e em algumas metodologias. Dialogar com os conteúdos é necessário, com os alunos, com a tradição, consigo mesmo. Desta forma poderemos propor que o pensar colabora para que minimizemos um dos sintomas da crise, a sensação de que não pertencemos a este mundo, um vazio de experiências formativas e de sentido. Pensar o pensamento de outros, as suas questões, compreender que elas surgem de uma experiência que se assume enquanto própria, conceber o ensino de filosofia nesse viés possibilita que aos alunos seja dada a oportunidade de eles mesmos constituírem novas questões pensando a filosofia e, a partir dela, pensarem e assumirem o próprio mundo no qual nasceram.

\section{Referências}

AGUIAR, Odílio A. Filosofia e política no pensamento de Hannah Arendt. Fortaleza: UFC Edições, 2001.

ALMEIDA, Vanessa S. A distinção entre conhecer e pensar em Hannah Arendt e sua relevância para a educação. Educação e Pesquisa, São Paulo, v.36, n.3, p. 853-865, set./dez 2010 .

ALMEIDA, R. M.; SCHÜLTZ, R. As intricadas relações entre educação e política em Hannah Arendt, in FÁVERO, A.A; CASAGRANDA, E.A. (org.) Leituras sobre Hannah Arendt: educação, filosofia e política. Campinas: Mercado de Letras, 2012.

ALMEIDA, Vanessa S. Educação em Hannah Arendt: entre o mundo deserto e o amor ao mundo. São Paulo: Cortez, 2011. 
ARENDT, Hannah. Crise na educação. In: Entre o passado e o futuro. 4. ed. São Paulo: Perspectiva, 1997.

ARENDT, Hannah. A condição humana. 12. ed. Rio de Janeiro: Forense Universitária, 2015.

ARENDT, Hannah. A dignidade da política. Rio de Janeiro: Relume-Dumará, 1993.

ARENDT, Hannah. A vida do espírito. 4. ed. Rio de Janeiro: Civilização Brasileira, 2014.

ARENDT, Hannah. Introdução na política. In: A promessa da política. Rio de janeiro: Difel, 2008.

ARENDT, Hannah. Que é autoridade. In: Entre o passado e o futuro. 4. ed. São Paulo: Perspectiva, 1997.

ASSY, Bethania. Ética, responsabilidade e juízo em Hannah Arendt. São Paulo: Perspectiva, 2015.

CARVALHO, José S. Educação, uma herança sem testamento. São Paulo: Perspectiva, 2017.

CARVALHO, José S. Reflexões sobre educação, formação e esfera pública. Porto Alegre: Penso, 2013.

DUARTE, André. Hannah Arendt: pensar a crise da educação no mundo contemporâneo. Educação e Pesquisa, São Paulo, v. 36, n.3, p. 823-837, set./dez. 2010.

LEFORT, Claude. Desafios da escrita política. São Paulo: Discurso Editorial, 1999.

PASSOS, Fábio A. O conceito de mundo em Hannah Arendt: para uma nova filosofia política. Rio de Janeiro: Lumen Juris, 2014.

VALÉE, Catherine. Hannah Arendt: Sócrates e a questão do totalitarismo. Lisboa: Instituto Piaget, 1999.

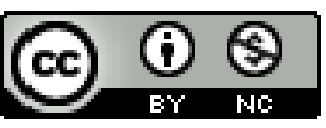

This work is licensed under a Creative Commons Attribution-NonCommercial 4.0 International (CC BY-NC 4.0) 